\title{
Commentary on "Deepithelized fasciocutaneous flap for labia majora augmentation during thigh lift. A case report" by AAH EI Danaf
}

\author{
Horacio F. Mayer
}

Received: 4 October 2010 / Accepted: 17 October 2010 /Published online: 5 January 2011

(C) Springer-Verlag 2010

The author presents an interesting novel technique for labia majora augmentation using adipofascial flaps from the inner thigh. As expected, the technique is only suitable for patients who are candidates for both labia majora augmentation and thigh lift. Such patients are becoming very common in clinical practice. On the one hand, over recent years, the number of patients undergoing bariatric procedures has skyrocketed. The main reason for this is the acceptance and success of laparoscopic techniques which require less recovery time. On the other hand however, the awareness of female genital esthetics has also increased owing to increased media attention, both from magazines and video. Many women feel self-conscious about the appearance of their labia majora and request surgical correction. In view of all of these, the presented technique seems a valuable addition to the plastic surgeon's armamentarium. The author should be congratulated for this contribution.

H. F. Mayer $(\bowtie)$

Plastic Surgery Department, Hospital Italiano de Buenos Aires,

University of Buenos Aires School of Medicine,

Buenos Aires, Argentina

e-mail: horacio.mayer@hospitalitaliano.org.ar 